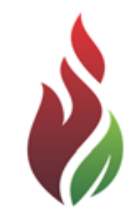

SUSTENERE

Publishing Corporation
ZRBADM

Journals Homepage:

www.sustenere.co/journals

\section{MÉTODO DE VALORAÇÃO CONTINGENTE E MAPAS AFETIVOS: PERSPECTIVAS PARA O PROCESSO DECISÓRIO}

\section{RESUMO}

Este artigo objetiva discutir a relação sujeito-ambiente sob a perspectiva de dois campos do conhecimento: Economia e Psicologia. Essa relação é apresentada por meio de dois métodos que buscam apreender aspectos envolvidos no ato de se atribuir um valor ao ambiental. O método da Valoração Contingente, estudada pela Economia. O método dos Mapas Afetivos analisa aspectos subjetivos e se insere no campo da psicologia ambiental, objetivando compreender as motivações subjacentes e o nível de apropriação dos sujeitos em relação ao ambiente. Os mapas se referem às dimensões envolvidas com o espaço. Busca entender as codificações, armazenamentos e atributos relacionados à experiência com o entorno. $\mathrm{O}$ instrumento possibilita identificar valores e significados atribuídos pelo sujeito e permite, inclusive, a apreensão de símbolos e aspectos culturais de um grupo. O método da valoração parece representar um avanço da tentativa de minimizar impactos ambientais. Sua limitação relaciona-se a forma de abordagem baseada em escolhas racionais. Sendo os sujeitos econômicos, detentores de aspectos que escapam a análise racional, não se pode afirmar que um sujeito ao definir um valor para um ativo ambiental, o faz por meio de critérios objetivos apenas. A combinação de metodologias diversas e a ampliação da discussão do ambiente possibilita uma compreensão mais holística dos fenômenos ambientais em interação com os sujeitos. Nesse sentido, possibilita a postura critica que torna o homem capaz de decidir entre várias alternativas segundo uma hierarquia de decisões e de afetos, processando suas escolhas a partir de convicções, atitudes, afetos, opiniões e pontos de vista em todas as circunstancias.

PALAVRAS-CHAVES: Mapas Afetivos; Valoração Contingente; Ambiente.

\section{CONTINGENT VALUATION METHOD AND AFFECTIVE MAPS: PERSPECTIVES FOR DECISION MAKING}

\section{ABSTRACT}

This article discusses the relation subject-environment from the perspective of two fields of knowledge: economics and psychology. This relationship is shown by two methods that seek to grasp aspects involved in the act of assigning a value to the environment. The Environmental Valuation, more specifically the method of the Contingent Valuation, is studied by Economy aiming aggregate externalities to economic analysis in order to minimize environmental impacts in planning and evaluating projects. The affective maps' method analyzes subjective aspects that belongs to the field of environmental psychology and aims to understand the underlying motivations and the level of ownership of the subject in relation to the environment. The combination of different methodologies and the expansion of the discussion of the environment allow for a more holistic understanding of environmental phenomena in interaction with the subjects and reveal themselves as possibilities to investigate the decisions of rational subject from its affective dimension. In this sense, it enables the critical posture that makes man able to decide between various alternatives according to a hierarchy of decisions and affections, suing your choices from beliefs, attitudes, feelings, opinions and views in all circumstances.

KEYWORDS: Affective Maps; Contingent Valuation; Environment; Decision-Making Process.
Revista Brasileira de

Administração Científica,

Aquidabã, v.5, n.3, Jul, Ago, Set,

Out, Nov, Dez 2014.

ISSN 2179-684X

SECTION: Articles

TOPIC: Gestão Ambiental

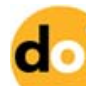

DOI: 10.6008/SPC2179-684X.2014.003.0016

Fabiana Pinto de Almeida Bizarria

Universidade de Fortaleza, Brasil http://lattes.cnpq.br/0008637422329772 bianapsq@hotmail.com

Mônica Mota Tassigny

Universidade de Fortaleza, Brasil http://lattes.cnpq.br/4109325305631925 monicam@secrel.com.br

Marcus Vinicius de Oliveira Brasil Universidade de Fortaleza, Brasil http://lattes.cnpq.br/1806063717574977 mvobrasil@ufc.br

Raimundo Eduardo Silveira Fontenele Universidade de Fortaleza, Brasil http://lattes.cnpq.br/5547677980453020 fontenele@unifor.br

Received: 17/02/2014

Approved: 15/11/2014

Reviewed anonymously in the process of blind peer.

\section{Referencing this:}

BIZARRIA, F. P. A.; TASSIGNY, M. M.; BRASIL, M. V. O.; FONTENELE, R. E. S.. Método de valoração contingente e mapas afetivos: perspectivas para o processo decisório. Revista Brasileira de Administração Científica, Aquidabã, v.5, n.3, p.273-286, 2014. DOI: http://dx.doi.org/10.6008/SPC2179684X.2014.003.0016 


\section{INTRODUÇÃO}

O tema dos limites da valoração da natureza representa um aspecto central da análise socioambiental por estudar relações entre a economia e o meio ambiente e os problemas ligados à agregação de preferências individuais dentro da análise custo / benefício tradicional. Além dessas relações, a psicologia ambiental traz concepções que podem aprofundar a compreensão de aspectos associados à sustentabilidade e a problemática ecológica global.

Objetiva-se fazer uma análise crítica da teoria neoclássica do meio ambiente, especialmente no que concerne a valoração do ambiente, tendo em vista que o processo decisório presente na valoração possui aspectos inerentes ao sujeito, referenciados na racionalidade limitada. Além disso, diante da possibilidade de agregar algumas sugestões para incluir as questões ambientais e de aspectos subjetivos no domínio de análise de projetos, será apresentada a metodologia dos mapas afetivos.

Este artigo pretende apresentar as concepções sobre racionalidade limitada e a racionalidade do procedimento de Simon (1965), entendendo esses conceitos como base para a reflexão crítica que possibilita a introdução da metodologia de apreensão dos afetos para se investigar os aspectos subjetivos da relação sujeito-ambiente no processo decisório da valoração ambiental.

Nogueira e Soublin (2000), no artigo sobre "A irracionalidade do indivíduo racional e a valoração do meio ambiente" apresentam alguns questionamentos que servem de pano de fundo para a reflexão proposta: "Como devemos expressar o valor e a importância que a natureza tem para nós? Como demonstramos o significado de nosso relacionamento com outros seres vivos? Como incluímos esses valores no processo, público e privado, de tomada de decisões?". Para tanto Nogueira e Soublin (2000) indicam que 'Psicologia e a economia se unem na busca de respostas para essas três perguntas'.

Para buscar subsídios para responder as questões levantadas, entra em análise a racionalidade limitada. Segundo Albuquerque e Escrivão (2005, p.3), baseado nos estudos de Simon (1965), "existem dois extremos nas ciências sociais quando o assunto tratado é a racionalidade". De um lado o homem econômico, que tem acesso a todas as informações e estímulos para mediar a melhor escolha. Do outro lado o conhecimento aliado à afetividade a partir de teóricos da teoria Freudiana. Os mesmos autores citam que "a pessoa busca a melhor solução, mas não a consegue devido às suas limitações ou critérios em que ela baseia a sua escolha" (ALBQUERQUE \& ESCRIVÃO, 2005, p.4).

Para Simon (1965), a tarefa de decidir envolve, entre outros aspectos, a avaliação de consequências relacionadas à escolha entre as alternativas, a partir de valores pessoais e organizacionais. Porém, não é possível ao homem, o conhecimento de suas alternativas e consequências de forma absoluta, tendo clareza de que suas escolhas são as melhores, embora suas análises das situações possam indicar que a opção é a melhor. "O que o indivíduo faz, na 
realidade, é formar uma série de expectativas das consequências futuras, que se baseiam em relações empíricas já conhecidas e sobre informações acerca da situação existente" (SIMON, 1965, p.81).

Nesse sentido, Felipe (2008, p.6) acrescenta que "a racionalidade limitada trata da incapacidade paramétrica dos modelos mentais de considerar toda a complexidade do ambiente, enquanto que a racionalidade do procedimento trata de como os padrões subjetivos são construídos e [...] influenciam as decisões dos agentes econômicos". Esse autor também enfatiza que "a investigação do procedimento de construções de soluções racionais juntamente como modelos mentais e importantes porque indicam como se formam as percepções, a reação aos estímulos, o padrão de construção de soluções e as condutas individuais dos agentes econômicos" (FELIPE, 2008, p.6)

Segundo Mattos et al. (2002, p.4), a investigação sobre "a valoração ambiental é essencial, caso se pretenda que a degradação da maioria dos recursos naturais seja interrompida antes que ultrapasse o limite da irreversibilidade". Essa questão é abordada por um filme denominado The Corporation, de 2003, quando se apresentam vários depoimentos sobre o impacto irreversível do meio ambiente, causados, em sua maioria, pelas corporações industriais.

Os métodos de valoração ambiental surgem com a premissa de não só "dimensionar impactos ambientais, internalizando-os a economia, mas também de evidenciar custos e benefícios decorrentes da expansão da atividade humana" (MATTOS et al., 2002, p.7). Além disso, o principal objetivo das análises custo-benefício (ACBs) é "a ideia dominante é a incorporação das externalidades dos impactos ambientais no cálculo dos custos e benefícios" (FONTENELE, 2006, p.1).

Assim, parte se da constatação de que "a internalização dos custos ambientais do processo produtivo [...] é uma excelente ferramenta para melhorar a alocação de recursos econômicos, mas é um processo que depende, basicamente, da identificação de impactos ambientais e de sua correta valoração econômica (MATTOS et al., 2002, p.8).

Embora a palavra 'correta' citada acima seja o que se pretende questionar no tocante a valoração, a apresentação da possibilidade de utilização paralela de outros métodos pode ser relevante para entender questões envolvidas no processo de escolha. Dessa forma, valorar um ambiente pode gerar discussões mais humanas e potencialmente mais efetivas, proporcionando uma análise mais coerente com os aspectos psicológicos dos sujeitos, que são atores sociais na perspectiva da sustentabilidade.

Partindo dessa reflexão pretende-se a construção da interface entre Psicologia, Ambiente e Economia, a partir da psicologia ambiental, por meio da análise afetiva do ambiente. Essa análise pode ser um ponto de interseção entre o processo de valoração econômica e os aspectos envolvidos na decisão do valor. Essa relação já foi apontada por Nogueira e Soublin (2000, p.1) quando cita que "a psicologia sistematicamente explora o comportamento, as escolhas e o bemestar humano. A economia também". 
Suas diferenças residem no fato da psicologia estudar o comportamento tendo por base "a natureza irracional que se usa inclusive de conteúdos emocionais para tomar suas decisões". Já os "Economistas [...] insistem em aplicar a antiga concepção de comportamento humano em diversas áreas da economia [...], a concepção do indivíduo racional e maximizado" (NOGUEIRA \& SOUBLIN, 2000, p.1).

Parte-se da premissa que as limitações do ser humano em decodificar todas as informações e estímulos que estão ao seu redor estão relacionadas a crenças, conflitos, culturas, poder, e aspectos de identificação e apropriação. Este artigo pretende argumentar que o uso de procedimentos constituídos baseado na análise de afetos, tendo como embasamento teórico a Psicologia Ambiental, poderia acrescentar características relacionadas aos afetos, e que podem agregar um nível mais profundo de conhecimento sobre o processo de escolha.

Este estudo visa apresentar um instrumento da psicologia ambiental, os mapas afetivos, na produção de pesquisas sobre valoração contingente. Esse instrumento metodológico tem por finalidade acessar os sentimentos por meio de desenhos. Bomfim (2003) reconhece o desafio que é trabalhar com emoções e sentimentos. Para se entender o pensamento e as escolhas de uma pessoa tornam-se necessário entendermos sua base afetivo-volitiva. Nesse sentido, os mapas afetivos podem relevar um caminho para acessar as motivações veladas nos significados das palavras. (FURLANI \& BOMFIM, 2010).

\section{METODOLOGIA}

Este artigo se caracteriza como ensaio teórico na busca de aprofundamento sobre o tema em análise. A metodologia empregada nesse artigo foi à pesquisa bibliográfica, tendo em vista a natureza do objetivo proposto que foi de apresentar dois métodos distintos, um estudado pela Economia e outro pela Psicologia no sentido de discutir suas relações a partir da teoria que embasa a Valoração Contingente e os Mapas Afetivos (GODOY, 1995). Outra característica sobre essa modelo de pesquisa é a comparação com a literatura conflitante, que permite criar validade interna, permitindo o aumento do nível teórico, tornando torna mais precisa a definição do constructo e a relação entre conceitos. (EINSENHARDT, 1995). A pesquisa fundamenta-se na metodologia qualitativa (DENZIN \& LINCOLN, 2006), buscando o entendimento do Coaching como uma ferramenta de inovação organizacional, no processo de desenvolvimento de pessoas em organizações. Esta metodologia revela-se como uma forma adequada para entender a natureza de um fenômeno social. (RICHARDSON, 1999).

\section{DISCURSÃO TEÓRICA}

\section{As limitações do Método Neoclássico para Avaliação dos Impactos Ambientais.}


Considerando a "nova configuração mundial, a ciência econômica deve necessariamente repensar sua posição relativa às outras ciências, e incluir variáveis não econômicas no planejamento de suas políticas" (SANTOS, 2000, p.2). Assim, a análise econômica requer um novo olhar para as questões de sustentabilidade e para a avaliação dos impactos ambientais. Busca-se "identificar que caminhos teóricos indicam uma maior aproximação da teoria econômica em relação à efetividade na busca de soluções locais e por consequência para a melhora nas condições de vida das pessoas" (SANTOS, 2000, p.2).

No que diz respeito ao método neoclássico, "no campo da avaliação de projetos [...], a ideia dominante é a incorporação das externalidades dos impactos ambientais no cálculo dos custos e benefício. [...] O meio ambiente é considerado uma coleção de bens e serviços, tendo valor instrumental" (FONTENELE, 2008, p.157).

A noção de externalidades, como uma capacidade de agregar os aspectos negativos do livre mercado a um valor monetário na perceptiva da análise econômica, é apresentada como uma possibilidade viável de atenuar problemas ambientais no âmbito do planejamento e da avaliação de projetos. Essa análise parte da concepção de se valorar o meio ambiente, por meio de declarações de preços. Para os autores que trabalham com esses conceitos, a quantificação do ambiente é um meio essencial para que se minimize a degradação dos recursos naturais. (MATOS et al., 2010).

O Valor Econômico dos Recursos Ambientais (VERA) representa um "um conjunto de técnicas e métodos que permite quantificar as expectativas de benefício e custos provenientes do uso de ativos ambientais, da execução de benfeitorias e da criação de danos ambientais." (MATOS et al., 2010, p.2). O VERA objetiva "o pagamento pelo uso ou manutenção dos recursos ambientais e tem a sua gênese na proteção de interesses atuais e futuros e a defesa de direitos inerentes à presença dos próprios recursos" (MATOS et al., 2010, p.3). Porém, esses autores indicam a dificuldade de trabalhar com essa estimativa de valor, visto que se espera agregar todos os efeitos negativos em um único indicador econômico.

O VERA classifica-se em Valores de Uso (VU) e Valores de Não-Uso (VNU). O primeiro, o VU, pode ser interpretado, ainda, por meio de três classificações: Valor de Uso Direto (VUD), Valor de Uso Indireto (VUI) e Valor de Opção (VO). No segundo caso, o VNU, se divide em duas possibilidades de análise, por meio dos Valores de Existência (VE) e os Valores de Legado (VL), (MATOS et al., 2010).

De forma resumida, essas nomenclaturas dizem o seguinte: O VU corresponde a um valor atribuído por pessoas que usam o recurso ambiental de forma a atender, de alguma forma, suas necessidades. Essa forma de usar o ambiente pode ser de forma direta (VUD), de forma indireta (VUI) e por opção (VO). O VNU é entendido como valor passivo e segue a seguinte lógica: a atribuição desse valor se inspira no posicionamento do sujeito como um ser cultural e ético. Além disso, se pauta no direito de garantia de sobrevivência de outras espécies de vidas. Esse valor de não uso é associado ao VE que define a presença de ativos ambientais no presente e no futuro. A 
preservação se pauta nas questões se respeito às demais espécies, como citado, e a garantia das convicções morais associadas a essa preservação (VL), (MATOS et al., 2010).

A limitação dessa abordagem já é apresentada por Motta (2011, p.182) que nos informa, por exemplo, que "na literatura, certa controvérsia com relação ao valor de existência representar o desejo do indivíduo de manter certos recursos ambientais para que seus herdeiros gerações futuras". Além disso, afirma que a questão das nomenclaturas citadas representa uma questão conceitual que de certa forma é irrelevante na medida em que, para a valoração ambiental, o desafio consiste em admitir que os indivíduos atribuam valor a recursos, mesmo que dele não façam qualquer uso.

O que faz da abordagem interessante, mas, ao mesmo tempo, nebulosa, consiste nela se situar na dimensão da escolha e se esperar que essa escolha seja proveniente de um ser racional. Segundo Lages (2006, p.53), "o problema de pesquisa neoclássica é o desafio para encontrar uma explicação para um dado fenômeno", considerando que este fenômeno pode ser visto como uma consequência lógica do comportamento maximizador - assim a maximização é posta como alguma coisa inquestionável.

Segundo Fontenele (2008, p.157) a teoria "neoclássica no campo do meio ambiente se baseia em duas hipóteses [...], os indivíduos são os melhores juízes de suas preferencias; as preferencias individuais são fundamento da avaliação dos bens mercantis e não mercantis". Assim, no campo das escolhas individuais surgem limitações quanto "a hipótese de racionalidade individual [...] com base no conceito de Disposição a Pagar, medir o valor de não uso de um bem ou serviço ambiental" (FONTENELE, 2008, p.158). Entretanto "uma série de ações públicas não pode ser decidida com base no princípio de decisão individual, mas em torno de uma abertura do debate junto da população beneficiada" (FONTENELE, 2008, p.158).

O Método Neoclássico parte "da opção metodológica de análise [...] que as pessoas escolhem como se elas estivessem maximizando sua função de utilidade esperada, como se isso fosse a situação normal, quando não é" (LAGES, 2006, p.53). Nesse aspecto, a utilidade esperada, diante de uma escolha subjetiva reserva a escolha o caráter instrumental como citado acima e reside em aparatos cognitivos. Assim, "estaríamos interessados apenas nas decisões alcançadas ou a curiosidade científica leva a investigar também como se desenvolver o processo humano de tomada de decisão?". (LAGES, 2006, p.54).

Partindo da questão levantada, este estudo compartilha da ideia que a "racionalidade substantiva mostra uma destacada incapacidade metodológica de satisfazer essa curiosidade" (LAGES, 2006, p. 54). Assim, cabe a reflexões propostas por outras ciências no sentido de buscar compreender o aspecto processual das escolhas econômicas. Também se aproxima da crítica feita por Fontenele (2006), quando afirma que: 
A metodologia que tenta medir o bem-estar subjetivo dos indivíduos, relativo à mudança na qualidade do meio ambiente, com base em métodos de sondagem se revelou extremamente operacional nesses últimos anos. Entretanto, quando se analisa a situação daqueles indivíduos que não dispõem de condições satisfatórias de vida, tais como uma quantidade suficiente de calorias, uma moradia decente e um digno nível de renda monetária, os resultados apresentamse contraditórios (FONTENELE, 2006, p.9).

Muitos fatores estão envolvidos no processo de escolha, desde o "fato de que os questionados são pouco familiarizados com o bem ou serviço" (FONTENELE, 2008, p.160). Percebem-se muitos vieses, como o "voluntario [...], quando o indivíduo questionado tem tendência a consentir, principalmente para obter aprovação social, [...], o viés instrumental [...] quando o valor atribuído ao bem pode variar em função do modo de pagamento" e o afetivo, que viabiliza encontros teóricos a partir da construção da Psicologia Ambiental (FONTENELE, 2008, p. 160).

Essa abordagem teórica é definida por Moser (2005, p. 281), "como sendo o estudo das inter-relações entre o indivíduo e seu ambiente físico e social, nas suas dimensões espaciais e temporais." Nesta perspectiva, a "adesão a uma posição determinista, ou mesmo interacionista, conduz certamente a reconhecer que o ambiente tem um efeito direto nas ações do individuo, [...] situando o indivíduo social, econômica e culturalmente". (MOSER, 2005, p.282).

Tendo em vista que, "o ambiente é geralmente considerado como uma construção daquele que o percebe" (MOSER, 2005, p. 282). Pergunta-se "qual é a relação entre Psicologia Ambiental e Política Ambiental?". (MOSER, 2005, p. 279). A partir da abordagem desse autor, este estudo se situa diante da necessidade de maior reflexão sobre o processo de escolha de valor, quando se trata de ambiente. Por isso, a abordagem do método de valoração econômica requer uma análise multidisciplinar.

\section{A Psicologia Ambiental e a Economia Ambiental}

A partir da década de 1970 e 1980, a psicologia ambiental se consolida como disciplina, com uma forte influência da chamada crise ambiental. Segundo Ferreira (2004) no Clube de Roma em 1978, e na Comissão mundial sobre o meio ambiente e desenvolvimento, promovido pela ONU, foram emitidas resoluções coletivas que apontam para a necessidade de mudanças nos modelos de produção econômica e de exploração dos recursos naturais vigentes no século XX. Essas iniciativas possibilitaram "estabelecer as condições para a reunião de informações sobre os níveis de degradação ambiental no globo terrestre" (FERREIRA, 2004, p.17).

Para ilustrar a tendência da psicologia ambiental nas discussões sobre sustentabilidade, Pinheiro (2003) reuniu diversas publicações e encontros que reunião o tema da psicologia ambiental a problemas ambientais e sustentabilidade. A relação da Psicologia ambiental a temas como a crise ecológica e ao comportamento pró-ambiental foram identificados na pesquisa citada como presentes, assim como o interesse pelo tema da sustentabilidade e aspectos sociais dos 
ambientes.

Outro dado observado por Pinheiro (2003), é que a Psicologia Ambiental é uma disciplina caracterizada por uma multiplicidade de enfoques, tanto teórico como metodológicos. Destaca-se o enfoque interdisciplinar, com principal ênfase na conexão entre psicologia ambiental e social. Os diversos enfoques em psicologia ambiental podem levar a entender a relação das pessoas com seu entorno físico, ou mesmo a compreensão desta disciplina a partir de diversos níveis de análise (individual, grupal e comunidade).

A psicologia ambiental é uma disciplina que trata da relação indivíduo-ambiente. Segundo Moser (2005), a psicologia ambiental tem por objeto o estudo e a compreensão dos processos psicossociais derivados das relações, interações e transações entre pessoas, grupos sociais e comunidades e seus entornos sócio-físicos. Além disso, como ramo da psicologia social destaca o entorno como parte da identidade dos indivíduos.

A relação indivíduo-ambiente não é entendida pela psicologia ambiental como sendo independente entre si. Essa corrente teórica estuda as inter-relações entre indivíduo e seu ambiente físico e social, nas suas dimensões espaciais e temporais. $\mathrm{O}$ ambiente é aqui entendido, segundo Moser (2005) como uma construção daquele que o percebe, não sendo um espaço neutro e isento de valores, ele é culturalmente marcado. O ambiente, enquanto tal veicula significações; nossa visão da natureza humana se exprime na maneira como nós moldamos o espaço construído; e este espaço construído retorna a nós, resignificando quem nós somos e o que devemos fazer (MOSER, 2005).

\section{Processos Psicológicos e o Ambiente: Os Mapas Afetivos}

Os mapas afetivos foram desenvolvidos por Bonfim (2003) em sua tese de doutorado na Espanha, onde foi investigada a afetividade de moradores das cidades de São Paulo e Barcelona. Esta metodologia de pesquisa foi constituída a partir do método de elaboração dos mapas cognitivos coletivos desenvolvidos por Lynch (1998). Esses mapas foram formulados na década de 50 e consistia na elaboração de desenhos que representassem ideias que uma pessoa atribui a memória que um determinado ambiente evoca. Os desenhos podem fazer parte da experiência direta do sujeito, ou pode surgir de imagens constituídas pelo conhecimento do ambiente a partir do relato de outras pessoas, da mídia, literatura etc.

Os mapas se referem às dimensões envolvidas com o espaço. Busca entender as codificações, armazenamentos e atributos relacionados à experiência com o entorno. $O$ instrumento possibilita identificar valores e significados atribuídos pelo sujeito e permite, inclusive, a apreensão de símbolos e aspectos culturais de um grupo. Na teoria de Lynch (1998), foi desenvolvido um estudo sobre a dimensão da estrutura e identidade dos mapas afetivos. Segundo Bonfim (2003), o significado como um componente simbólico elaborado pelo sujeito foi considerado nos estudos de Lynch (1998), porém não foi investigado mais enfaticamente. 
A partir dos estudos de Lynch (1998), Bonfim (2003) busca a construção de uma metodologia que referencie aspectos simbólicos e cita a perspectiva histórico-cultural de Vygotsky (1991) sobre a relevância de se investigar os afetos nos processos interativos. O autor (2003) apresenta as possibilidades transacionais dos mapas que são entendidos como figurativos e abstratos. Os mapas abstratos representam um maior interesse para o trabalho do referido cientista (2003), pois enfatiza a possibilidade de se explorar recursos emotivos e expressivos a partir da construção de imagens. Bonfim (2003) define os mapas afetivos como:

Imagens ou representações assentadas em sinais emotivos ou expressivos, elaborados a partir de recursos imagéticos (desenhos, fotos, objetos de arte). Afirmamos que eles são reveladores da implicação do indivíduo a um determinado ambiente: casa, bairro, comunidade, cidade. Podem ser gerados a partir de mapas cognitivos, porém seu maior objetivo não é a orientação espacial ou a localização geográfica. Eles são orientadores das estratégias de ação e avaliação dos níveis de apropriação (pertencer ou não pertencer a um lugar), apego (vinculação incondicional a um lugar) e de identidade social urbana (conjunto de valores, representações, atitudes que tomam parte da identidade do indivíduo no lugar). Como sínteses dos afetos, eles também apontam o nível de implicação do indivíduo no lugar. Dado seu caráter representacional e criativo, são recursos de acesso à dialética subjetividade / objetividade na cidade (BOMFIM, 2003, p.35).

Com o objetivo de acessar os conteúdos afetivos a partir do recurso imagético, "a autora visava romper com as dicotomias comuns em investigações das ciências humanas em geral, e da psicologia em particular, como razão-emoção, subjetividade-objetividade, mente-corpo, sujeitoambiente" (VIANA, 2009, p.31). O instrumento gerador dos mapas afetivos é composto pelos seguintes itens: desenho, significado do desenho, sentimentos, palavras sínteses e categorias da escala Likert. O instrumento final dos mapas afetivos, segundo Viana (2009, p.35), "ficou organizada de modo a permitir a visualização dos dados em um quadro que apresenta as seguintes dimensões: identificação do respondente, estrutura do desenho, significado, qualidade, sentimento, metáfora e sentido", como segue:

Quadro 1: Mapa Afetivo Original.

\begin{tabular}{|c|c|}
\hline \begin{tabular}{|l|} 
Identificação \\
\end{tabular} & Estrutura \\
\hline & $\begin{array}{l}\text { Mapa cognitivo: } \\
\text { de Lynch: } \\
\text { desenho do } \\
\text { monumento, } \\
\text { caminhos, }\end{array}$ \\
\hline $\begin{array}{l}\text { Sexo: } \\
\text { Escolaridade: } \\
\text { Cidade: Tempo } \\
\text { de residência } \\
\text { (quando não } \\
\text { originário): }\end{array}$ & $\begin{array}{l}\text { limites, } \\
\text { confluência e } \\
\text { bairros } \\
\text { Mapa } \\
\text { metafórico: } \\
\text { desenho que }\end{array}$ \\
\hline & $\begin{array}{l}\text { expressa, por } \\
\text { analogia, o } \\
\text { sentimento ou o } \\
\text { estado de ânimo } \\
\text { do respondente }\end{array}$ \\
\hline
\end{tabular}

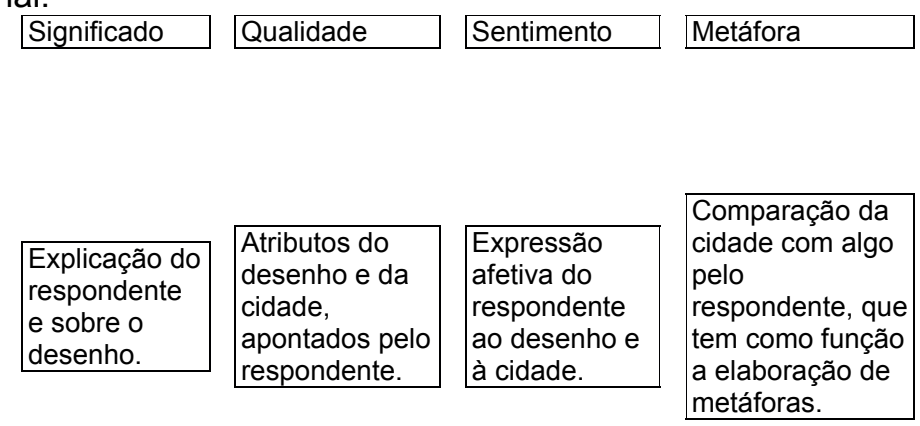
Sentido Interpretação dada pelo investigador à articulação de sentidos entre as metáforas da cidade e as outras dimensões atribuídas pelo respondente (qualidade e sentimentos).

Fonte: Bomfim (2003, p.144). 


\section{Os Métodos da Economia Ambiental: em Análise a Valoração Contingente.}

Com os problemas ambientais surgiu uma maior necessidade de se analisar as questões ambientais sob o ponto de vista econômico. Na busca de proteção do meio ambiente, os conceitos e instrumentos sobre economia ambiental passaram possibilitar um melhor direcionamento para as decisões públicas. Nesse sentido, os objetivos de valorar o ambiente podem ser resumidos sob a ótica de Hildebrand et al., (2002), como a necessidade de estimar os benefícios e as perdas relacionados aos recursos ambientais, a partir de medidas constituídas para mediar comparações e auxiliar nas decisões financeiras.

Os Métodos de Valoração Econômica ambiental são instrumentos analíticos que possuem diversas aplicações. $O$ uso dessas ferramentas para estudos e avaliações de politicas se mostra promissor. "Embora limitados, os valores monetários calculados são ferramentas úteis nas decisões de políticas públicas. Confrontando-os com aplicações alternativas, podem-se escolher os projetos com maiores potencialidades de ganho de bem-estar social" (NOGUEIRA et al., 2000).

Já o Método de Valoração Contingente "utiliza a técnica do questionário para avaliar as preferências dos consumidores, os quais descrevem nitidamente o bem a quantificar. (...) Sendo um método das preferencias expressas dos indivíduos, os inquéritos sobre o bem que está a ser valorado devem descrevê-ló nitidamente para que não haja falhas de comunicação. (MATOS et al., 2010, p.9). Segundo Mattos et al., (2002, p.9) "o valor pode ser interpretado de diversas formas, embora para Pearce e Turner (1991) existem três relações dos valores ambientais (...): valores expressos via preferencias individuais; valores de preferência publica; e valores do ecossistema físico funcional”.

Para Motta (1998, p.1), "determinar o valor econômico de um recurso ambiental é estimar o valor monetário deste em relação aos outros bens e serviços disponíveis na economia". "As pessoas atribuem esses valores de acordo com a avaliação que fazem da singularidade e da irreversibilidade da destruição do meio ambiente, associadas à incerteza da extensão dos seus efeitos negativos" (MATTOS, 2000, p.9).

De acordo com Nogueira e Soublin (2000, p.1), "tem se tornado cada vez mais frequente o uso de métodos de valoração do meio ambiente onde um comportamento humano racional e maximizador é simulado". Um método utilizado com esse objetivo é o Método de Valoração Contingente (MVC), que, por exemplo, tem crescido em popularidade entre economistas desejosos de obter valores para bens públicos e ambientais. Este método busca:

simular cenários, cujas características estejam o mais próximo possível das existentes no mundo real, de modo que as preferencias reveladas nas pesquisas reflitam decisões que os agentes tomariam de fato caso existisse um mercado para o bem ambiental descrito no cenário hipotético. As preferencias, do ponto de vista da teoria econômica, devem ser expressas em valores monetários. Estes valores são obtidos através das informações adquiridas nas respostas sobre quanto os indivíduos estariam dispostos a pagar para garantir a melhoria de bemestar, ou quanto estariam dispostos a aceitar em compensação para suportar uma perda de bem-estar. (MOTTA, 1998, p.32). 
Este método utiliza medidas de "disposição a pagar (DAP) e aceitar (DAA), [...] com base em mercados hipotéticos" (MOTTA, 1998, p.32). Essa valoração "é realizada em pesquisas de campo, com questionários que indagam ao entrevistado sua valoração contingente (DAA ou DAP) face as alterações na disponibilidade de recursos ambientais" (MOTTA, 1998, p.32).

De acordo com Motta (1998, p.36) a crítica em relação ao Método da Valoração Contingente (MCV), diz respeito a "sua limitação em captar valores ambientais que indivíduos não entendem, ou mesmo desconhecem [...] Se as pessoas são capazes de entender claramente a variação ambiental que está sendo apresentada na pesquisa [...] então este método pode ser considerado ideal". Porém, como afirma Motta (1998), muitos fatores podem "levar à discrepância entre as preferencias reveladas nas pesquisas e as verdadeiras preferencias". E partimos dessa firmação para associar o fator subjetivo associado à escolha, como fator que diferencia os valores de DAP ou DAP de acordo com os níveis de apropriação e identificação com o ativo ambiental.

No que diz respeito aos vieses, a confiabilidade e a validade desse método, Motta (1998, p.38) aponta várias questões a serem observadas pelos pesquisadores que optarem por este método. Uma delas refere-se "ao grau de realismo dos cenários construídos no MVC e a familiaridade dos entrevistados com estes cenários". Baseado nessa relação de familiaridade com os cenários que este artigo apresenta o método dos mapas afetivos como um instrumento de investigação desse grau de familiaridade a partir dos afetos e, assim, empreender uma valoração contingencial tendo como referência a análise dos afetos.

Esta investigação vai além da "hipótese de racionalidade individual [...] com base no conceito de disposição a pagar, medir o valor de não uso de um bem ou serviço ambiental". Quando se fala em desenvolvimento sustentável, por exemplo, "o princípio da racionalidade do consumidor apresenta uma limitação", baseada nas preferências individuais que podem estar "na direção contraria ao interesse dos outros indivíduos". Percebe-se que a avaliação dos valores individuais agregados aos ambientes valorados é essencial. "Nesse contexto, sugere-se que uma série de ações públicas não pode ser decidida com base no princípio de decisão individual, mas em torno de uma abertura do debate junto da população beneficiada" (FONTENELE, 2008, p. 4). Ainda segundo o autor (2008):

A base de sustentação teórica do modelo neoclássico para tratar das questões ambientais está centrada na função de bem-estar individual, em termos de utilidade ou de satisfação das preferencias individuais, medidas pela disposição a Pagar ou a Receber. Mas, na realidade, discute- se a veracidade cientifica do referido critério. Como é possível admitir, dentro de uma abordagem individualista, que a apreciação dos diferentes estados da sociedade dependa do nível de satisfação individual de todos os agentes? De fato, a resposta a essas indagações é problemática, na medida em que a comparação daquilo que não é possível comparar fidedignamente, em termos monetários, pode conduzir a contradições na análise dos critérios de rentabilidade (FONTENELE, 2008, p. 9). 


\section{CONCLUSÕES}

A possibilidade de realizar preservação ambiental desperta, de forma animadora, inquietação diante dessa problemática. Os estudos econômicos tem se debruçado na busca de formas de driblar as externalidades e os impactos causados ao ambiente, principalmente em virtude da lógica do consumo. O planejamento de novos projetos precisa aferir de forma qualitativa e quantitativa que tipo de impactos ambientais essas iniciativas podem desencadear. Assim, a avaliação de projetos, partindo da perspectiva ecológica, deve utilizar métodos variados na tentativa de apreender aspectos econômicos e aspectos subjetivos. Pode-se inferir que os limites da valoração da natureza é um tema relevante para a análise socioambiental. Assim, a apresentação de um novo instrumento que possibilite essa análise de forma mais abrangente se revela como um aspecto que pode aprofundar a compreensão de estudos sobre sustentabilidade e sobre a problemática ecológica global.

O método da valoração parece representar um avanço da tentativa de minimizar impactos ambientais. Sua limitação relaciona-se a forma de abordagem baseada em escolhas racionais. Sendo os sujeitos econômicos, detentores de aspectos que escapam a análise racional, não se pode afirmar que um sujeito ao definir um valor para um ativo ambiental, o faz por meio de critérios objetivos apenas. Este artigo objetivou apresentar uma forma complementar a análise econômica tendo como referência dados subjetivos, por meio da utilização de mapas afetivos. A tentativa de compreender os fenômenos de forma holística e com a apreensão de um maior número de informações e variáveis, justifica a possibilidade de escolha de outros métodos para se compreender o que um sujeito está disposto a pagar, observando sua relação afetiva com o ambiente.

A relação sujeito-ambiente, tanto para a econômica, como para a psicologia representa um aspecto essencial para tomadas de decisão na tentativa de se buscar relações equilibradas. A distribuição de ganhos e perdas se pauta no envolvimento dos sujeitos nesses ganhos e perdas e na possibilidade de que suas escolhas sejam referenciadas pelo compromisso ambiental, aspecto que deve ser estimulado por meio de qualquer tipo de análise econômica, na construção de atitudes e comportamentos economicamente sustentáveis.

Considerando as concepções sobre racionalidade limitada de Simon (1965), e a reflexão crítica sobre o processo decisório, que foram abordados nesse artigo por meio da sugestão de uma abordagem proveniente da psicologia, a metodologia de apreensão dos afetos para se investigar os aspectos subjetivos da relação sujeito-ambiente no processo decisório da valoração ambiental, revela-se como uma possibilidade de investigar as decisões do sujeito racional a partir de sua dimensão afetiva. Nesse sentido, possibilita a postura crítica que torna o homem capaz de decidir entre várias alternativas segundo uma hierarquia de decisões e de afetos, processando suas escolhas a partir de convicções, atitudes, afetos, opiniões e pontos de vista em todas as circunstancias. 


\section{REFERÊNCIAS}

ALBUQUERQUE, A. F.; ESCRIVÃO FILHO, E.. Administrar é decidir: a visão de Herbert Simon. Revista DCS On Line, v.1, n.1, 2005.

BOMFIM, Z. A. C.. Cidade e afetividade: estima e construção dos mapas afetivos de Barcelona e São Paulo. Tese (Doutorado) - Pontifícia Universidade Católica de São Paulo, São Paulo, 2003.

GODOY, A. S. A.. Pesquisa qualitativa e sua utilização em Administração de empresas, Revista de Administração de Empresas, São Paulo, v.35, n.4, p.65-71, 1995.

DENZIN, N.; LINCOLN, Y.. Handbook of Qualitative Research. Thousand Oaks: Sage, 1994.

EINSENHARDT, K. M.. Studying Processes of Organizational Change. Thousand Oaks: Sage Publications, 1995.

FELIPE, E. S.. Racionalidade limitada e modelos mentais: aspectos cognitivos dos agentes econômicos na economia institucionalista. Revista de Economia, v.34, n.3, 2008.

FERREIRA, M. R.. Problemas ambientais como desafio para a psicologia. Campinas: Alínea, 2004.

FONTENELE, R. E. S.. Análise crítica da internalização de impactos ambientais nas análises custosbenefícios (ACB) de Projetos. In: ENCONTRO DA ANPAD. 30. Anais. Salvador: ENANPAD, 2006.

FONTENELE, R. E. S.. Analise crítica da valoração monetária do meio ambiente nos métodos neoclássicos de avaliação econômica de projetos. RAC-Eletrônica, v.2, n.1, p.155-170, 2008.

FURLANI, D. D.; BOMFIM, Z. Á. C.. Juventude e afetividade: tecendo projetos de vida pela construção dos mapas afetivos. Psicologia Social. v.22, n.1, p.50-59, 2010.

HILDEBRAND, E.; GRAÇA, L. R.; HOEFLICH, V. A.. Valoração contingente na avaliação econômica de áreas verdes urbanas. Floresta. v.32, n.1, p.121-132, 2002.

LAGES, A. M. G.. A contribuição singular de Simon e sua repercussão teórica relevante. Porto Alegre, v.1, n.1, 2006.

LYNCH, K.. La Imagen de la Cidad, Barcelona: Editorial Gustavo Gil, 1998.

MATOS, A.. Análise Crítica dos Métodos de Valoração Econômica dos Bens e Recursos Ambientais. Cáceres: Universidade da Estremadura, 2010.

MATTOS, K. M. C.; NEUCLAIR FILHO, J. F.; MATTOS, A.. Uma abordagem conceitual sobre a Valoração Econômica de Recursos Naturais. In: SIMPÓSIO SOBRE RECURSOS NATURAIS E SÓCIO-

ECONÔMICOS DO PANTANAL. 3. Anais. Corumbá: Embrapa, 2002.

MOTTA, R. S.. Manual para Valoração Econômica de Recursos Ambientais. Brasília: Ministério do Meio Ambiente, dos Recursos Hídricos e da Amazônia Legal, 1998.

MOTTA, R. S.. Valoração e Precificação dos Recursos Ambientais para uma economia verde. Belo Horizonte: Economia Verde, 2011.

MOSER, G.. A Psicologia ambiental: competência e contornos de uma disciplina. Psicologia USP, v.16, n.1, p.279-294, 2005.

NOGUEIRA, J. M.; MEDEIROS, M. A. A.; ARRUDA, F. S. T.. Valoração econômica do meio ambiente: ciência ou empirismo?. Cadernos de Ciência \& Tecnologia, Brasília, v.17, n.2, p.81-115, 2000.

NOGUEIRA, J. M.; SOUBLIN, V. C. C. M.. A irracionalidade do individuo racional e a valoração do meio ambiente. In: ENCONTRO ANUAL DA SOCIEDADE BRASILEIRA PARA PROGRESSO DA CIÊNCIA (SBPC). 52. Anais. Brasília: SBPC, 2000. 
PINHEIRO, J. Q.. Psicologia ambiental: espaços construídos, problemas ambientais, sustentabilidade. Estudo Psicologia, v.8, n.2, p.209-213, 2003

RICHARDSON, R.J.. Pesquisa social: métodos e técnicas. São Paulo: Atlas, 1999.

SANTOS, R. B.. Relações entre meio ambiente e ciência econômica: reflexões sobre economia ambiental e a sustentabilidade. Curitiba: Universidade Federal do Paraná, 2000.

SIMON, H. A.. Comportamento administrativo: estudo dos processos decisórios nas organizações administrativas. 2 ed. Rio de Janeiro: Fundação Getúlio Vargas, 1965.

VIANA, L. G.. Afetividade ambiente esportivo: sentimentos e emoções de atletas de competição. Tese (Dissertação de Mestrado) - Universidade Federal do Ceara, Fortaleza, 2009.

VYGOTSKY, L. S.. A construção do pensamento e linguagem. São Paulo: Martins Fontes, 2001. 